\title{
Age and Support for Public Debt Reduction
}

\author{
Alessia Aspide Kathleen J. Brown Matthew DiGiuseppe \\ Leiden University Leiden University Leiden University* \\ Alexander "Xander" Slaski \\ Leiden University ${ }^{\dagger}$
}

June 11, 2021

Prepared for the European Political Science Association Annual Meeting 2021

\begin{abstract}
Many scholars and policymakers see the continuing rise of debt burdens in the advanced industrialized world as the product of aging populations and increasing dependency ratios. In fact, many prominent theoretical models of government debt accumulation - often used to justify fiscal rules and austerity measures - make explicit assumptions that individuals will have different preferences for debt reduction as they age. While such models have been influential, the fundamental assumption regarding the relationship between age and preferences for growing debt has not been test empirically. Using a decade's worth of data from the Eurobarometer survey across 28 countries, we find that age has a modest, non-linear impact on concern for national debt burdens. In general, the middle-aged show the most concern for debt reduction, while the young and the old are less likely to view reducing government debt as a policy priority. Notably, the relationship is strongest in countries with more generous old-age benefits.
\end{abstract}

${ }^{*}$ corresponding author: m.r.di.giuseppe@fsw.leidenuniv.nl

${ }^{\dagger}$ The authors would like to thank Jaroslav Kantorowicz for early comments. We would also like to thank Alexandre Diogo and Nina Waals for the their research assistance. This reasearch was funded with European Research Council Grant 852334 (The Microfoundations of Debt Crises) 
Across Europe and other advanced industrialized economies, longer life expectancies and lower fertility rates have created a population pyramid with an ever-greater proportion of individuals in retirement age and fewer working-age individuals paying the taxes to support those programs (Harper, 2014; Bogetic et al., 2015). One of the most salient consequences of this dramatic demographic shift is its impact on fiscal policy (Pench, 2020). The combination of growing fiscal demands from those receiving pensions and a shrinking number of productive workers - a rising dependency ratio - creates an enormous fiscal challenge. As retiring workers are replaced at a slower rate by new births or immigration, fewer and fewer prime-age workers will be financing pay-as-you-go pensions and social programs. Economists predict that the underlying trend creating this financial challenge has and will continue to contribute to even higher government debt burdens and eventually force countries to make difficult choices over fiscal priorities (Yared, 2019).

In addition to the unprecedented fiscal challenge, aging populations present a political problem. Debt-financed fiscal policy allows the inter-temporal transfer of wealth from future to current generations. As such, it raises the prospect for inter-generational conflict if the aging process affects preferences for the composition of government fiscal policy and repaying existing liabilities. Political economy models of fiscal deficits and growing debt burdens have long identified the risk of such conflict and often attribute growing debt burdens to these demographic shifts (e.g. Cukierman and Meltzer, 1989; Tabellini, 1991). In particular, scholars have argued that because aging individuals will not bear the future costs of debtfinanced spending, they have a strong incentive to delay tax increases and spending cuts in old age. The implication is that, as societies age, governments will not have political support to maintain healthy fiscal balances or reign in high debt burdens. Such problems are compounded as the elderly become a larger proportion of the voters who dictate fiscal priorities, especially given that the elderly tend to vote at higher rates than the young (Goerres, 2007). 
An aging, active voter population lends urgency to testing the intergenerational conflict assumption at the heart of prominent political economy models of debt (Cukierman and Meltzer, 1989; Tabellini, 1991; Song et al., 2012; Bisin et al., 2015; Yared, 2019) that are often used to advocate for controversial policies like fiscal rules that can limit a government's investment in society (Andersen, 2019; Acemoglu and Yared, 2010). While intergenerational conflict over debt is a widely used assumption in the debt literature, the assumption has not been widely tested. Furthermore, skepticism of a generational divide over fiscal policies is warranted as expectations of inter-generational conflict over spending priorities are not borne out in the data. Differences in preferences for types of spending by different age groups (e.g. education and healthcare) are apparent. However, these differences are relatively small (Sørensen, 2013) and do not reflect broader differences in support for political parties (Goerres, 2009). In fact, much of the existing research has found that generational issues are more pronounced with regards to social rather than economic issues (O'Grady, 2018, 2020). This is consistent with existing research that emphasizes political attitudes are relatively stable over adulthood (Hatemi et al., 2009; Prior, 2010).

We aim to systematically test the relationship between age and political preferences over debt politics but also theorize further about the relationship. Existing models often assume two generations - for the sake of tractability - that imply a linear relationship between age and support for debt reduction. We build on this by incorporating insights about economic incentives drawn from life-cycle consumption smoothing expectations (Modigliani and Brumberg, 1954). We posit that age should have a non-linear impact on preferences for government debt policy. Those who have yet to enter the workforce or expect higher future wage growth should have an incentive to oppose higher taxes or cuts to social spending. Next, as individuals begin to rely on pensions and social spending, they should prefer to postpone debt consolidation until the burden falls disproportionately on the next generation. Those between these two groups should show the most concern over government debt. 
We draw on twenty waves of the Eurobarometer survey, administered twice per year between 2010 and 2019, to test the relationship between age and debt. Our aggregate findings are largely consistent with our life-cycle hypothesis. Support for debt reduction is low among the young, increases through middle age, and then begins to decrease as respondents age. Yet, the effect is modest and the relationship does not hold in all contexts as there is non-trivial heterogeneity across countries and time. Further analysis reveals that the relationship appears strongest in countries that have the most generous public spending schemes. Lastly, we offer an important caveat. The length of our panel limits our ability to definitively disentangle the effects of age and cohort (Yang and Land, 2016). While we take several steps to address confounding by cohort effects, we statistically cannot rule out that the effect of age is a product of the attitudes of the current cohort of elderly Europeans and may not reflect the attitudes of the next generation as they age.

These results have important implications for economics and political science research on public debt. Voter preferences often serve as a foundational assumption of political economy models. However, untested assumptions make model validation and comparison difficult. This is especially problematic when testing model predictions is only possible with observational country-year level data. Our results lend some support to models that depend on assumptions of inter-generational conflict. However, our results suggest that theoretical models should be adapted to consider a non-linear relationship between age and support for public debt reduction.

Our findings also speak more directly to the growing literature on the mass politics of public debt. Much of this work focuses on post-crisis politics, with minimal focus on the events that cause those crises (Curtis et al., 2015; Nelson and Steinberg, 2018). As a result, the existing research on the accumulation of public debt and other pre-crisis events is much more limited, leaving many unanswered questions about the conditions under which crises emerge. While others have shown that party politics and proposal characteristics play 
important roles in shaping non-crisis debt preferences (Barnes and Hicks, 2018; Bansak et al., 2020), we demonstrate that structural factors are also important.

Lastly, our research engages with the growing literature on the consequences of a graying society and intergenerational political conflict and seeks to provide a corrective to the parts of the literature that emphasize how intergenerational conflicts in Europe escalates because of aging populations (Sinn and Uebelmesser, 2003).

\section{Aging Societies and Public Debt}

The "graying" of society is likely to impact the preferences for and management of government debt in two ways. The first is through the composition of public spending and revenue, with less government revenue coming from workers and increased expenditure on social programs designed to support the elderly, with important consequences for the fiscal positions of governments. Several factors contribute to the effect of aging on fiscal stability: the tax base shrinks as workers retire, older citizens consume less than prime-age workers, and the cost of government health services for elderly patients increases (Yoshino et al., 2019). Moreover, given longer life expectancy, pension schemes must provide benefits for much longer than policymakers had originally anticipated (and budgeted for) (Sinn and Uebelmesser, 2003). An aging society is also likely to lead to lower economic growth as there are fewer producers, consumers, and innovators in the workforce (Lee, 2016). While government spending driven by the demands of the elderly may offset some of this decline, the fiscal multiplier for spending on old-age related programs will likely be lower than the same amount of spending targeted towards younger voters (Basso and Rachedi, 2018). This lower growth will make it harder for governments to roll over and repay existing debts (Fuest and Gros, 2019). Given the fiscal consequences of aging populations, it is not surprising that there is a strong correlation between population age and government debt (Yared, 2019). 
The second way that aging can impact public debt is via a shift in political preferences towards the interests of elderly voters. Several scholars, mainly within economics, have developed models to explain how the intertemporal nature of debt will influence intergenerational conflict over repayment, including the associated combination of spending cuts and tax increases. There are three related causal mechanisms by which an aging population might influence political preferences for debt reduction and policies to reduce deficit spending. Each has its origin in the Diamond-Samuelson overlapping generations model of fiscal policy in which debt enriches some generations at the expense of others (Diamond, 1965; Mankiw and Elmendorf, 1999).

First, Cukierman and Meltzer (1989) and Tabellini (1991) consider the straightforward proposition that generations might differ in their preferences for transferring income between generations through borrowing. Cukierman and Meltzer (1989) suggest that if a majority of individuals do not wish to bequeath wealth to later generations, they have an incentive to support policies that result in lower taxes today and the accumulation of government debt. Tabellini (1991) extends this scenario and suggests that the actions of the elderly, by saddling future generations with large debt burdens, actually contribute to intra-generational future conflict between the wealthy and poor over reduction of public debt.

Second, Song et al. (2012) assume that younger voters have a greater interest in the future provision of public goods, given that they are currently paying taxes and have a longer time horizon than the elderly. For example, within the context of the United States, younger voters may also wish to benefit from social security, social spending for the elderly, or even the fiscal space to confront economic crises, wars, recessions, and other unforeseen events. As such, they prefer to limit the size of the national debt to allow for future borrowing, prevent government spending from becoming constrained in the present, and reduce the need for future austerity or tax increases. Sparing the complexities of the formal theoretical model, they predict that as the proportion of younger voters shrinks, fiscal policy will become more 
focused on contemporary public goods consumed by the elderly leading to increases in public debt. This model has been used as a framework for a variety of work on ageing fiscal policy (Bisin et al., 2015; Andersen et al., 2006; Magistretti, 2019), with some extensions suggesting that market discipline, via creditor demand for higher interest rates, will dampen the impact of aging on debt. However, this will likely come with additional social costs and increase pressure to default when it becomes more difficult to roll over existing debt, as debt ceilings are reached, creditors lose faith and credit ratings fall, and spending becomes constrained.

Third, other scholars have approached the question in a slightly different way, assuming that the rate at which households discount the future is heterogeneous (Yared, 2019). Simply put, older voters exhibit a higher present-bias and will therefore favor higher deficits in policy choice with future implications. As these aging and impatient households become a greater share of the electorate, this theorizing predicts that the government will become more shortsighted, deficits will grow, and debt will accumulate.

Each of these models makes assertions about the generational preferences for debt reduction that, if the models are informative, provide a strong reason to believe aging societies influence debt burdens not only through a dwindling workforce and need for social spending but also because aging interests shape the politics of debt reduction. While they make clear predictions about the political impact of a graying society, there is little empirical evidence to substantiate the claim that the elderly are more present-biased in their policy preferences or are more concerned about their private goods than the public good of future fiscal space. Furthermore, literature outside of study of public debt suggests that fears of generational conflict from an aging society maybe overstated.

\section{Intergenerational Politics}

The larger debate over the degree to which politics will be dictated by the elderly rests on the assumption that there are differences in political preferences between older and younger 
generations. Some studies claim that when old people are confronted with a trade-off between spending on education or pensions and health, the age effect skews preferences in favor the later option (Cattaneo and Wolter, 2009; Busemeyer et al., 2009). However, the literature that predicts generational conflicts often neglects cohort and period effects, assuming that such conflicts are driven by the aging process itself, or centers the analysis on one country as a case study, making any finding hardly applicable to other countries (Sørensen, 2013). In addition, O'Grady (2020) investigates whether Europe is likely to become a "gerontocracy," concluding that the overall age cleavage in European politics has not increased over the past thirty years as Europe has aged. Indeed, there is only weak evidence to support the claim that increasing age differences among citizens supersedes traditional conflicts across social classes and political ideologies (Naumann, 2018).

Even scholars that conclude age is a relevant predictor of preferences towards educational spending, such as Busemeyer et al. (2009), remark that the portrayal of generational conflict overstates its importance and that the salience of age for preferences varies significantly across countries. In addition, the preferences of elderly voters for health spending and pensions over education is not necessarily at odds with younger generations' preferences. While old people can no longer economically benefit from education, young people seem to acknowledge that they will be the future beneficiaries of policies designed to assist the elderly (Bonoli and Häusermann, 2009). Young people may support pro-elderly policies out of compassion for those who are currently old (Huddy et al., 2001), and the lack of a strong age-based conflict over education spending suggests that there is substantial overlap in the preferences of young and old voters. Moreover, the elderly may also show intergenerational solidarity by interacting with other generations in their family and internalize the well-being of younger generations in their utility function (Goerres and Tepe, 2010).

If demographic shifts do not intensify overall generational conflicts, then apparent differences in preferences could be explained in light of cohort and period effects (Grasso et al., 
2019; O'Grady, 2020). For example, in the case of climate and environmental policy, a field characterized by intergenerational conflicts over the future burdens of environmental damage and short-term costs of adjustment, it is unclear if conflicts are induced by a genuine age effect or by a cohort effect. Existing research shows that elderly voters are less concerned about tackling climate change and less likely to allocate public funds to environmentally friendly policies (Andor et al., 2018; Hersch and Viscusi, 2006), but it has not been demonstrated that this is an effect of aging rather than a result unique to the cohort of elderly voters under investigation. Alternative explanations include the idea that old people may be more skeptical about the existence of climate change or the fact that it is caused by human activity (Bohr, 2017; Andor et al., 2018) and may generally be more insulated from information about environmental risks (Hersch and Viscusi, 2006).

In summary, debt is not the only issue area where scholars have theorized about the possibility of intergenerational conflict resulting from age-based demographic shifts. In line with the standard assumption of political economy models that individuals are driven primarily by material self-interest, several researchers have sought to find evidence that the young and old are likely to have diverging policy preferences and political behavior in a time of aging population (Sinn and Uebelmesser, 2003; Cattaneo and Wolter, 2009). Yet, much of this research finds that fears of a broad shift towards policies that reflect the interests of the elderly are overblown (Emery, 2012; Sørensen, 2013; Naumann, 2018; O'Grady, 2020) and that interpreting political preferences as driven by pure age-based self-interest is oversimplified (Goerres and Tepe, 2010). Before conclusive claims can be made about the effect of graying politics on policy, the relationship between age and preferences demands further investigation. 


\section{Testable Hypotheses}

We test the assumption made in many prominent theories of sovereign debt politics that preferences towards debt policy are a function of age. The most straightforward claim apparent in the literature suggests a linear relationship with age, with older individuals being less worried about debt given their shorter time horizons (Cukierman and Meltzer, 1989; Tabellini, 1991; Song et al., 2012; Yared, 2019).

Hypothesis 1. Individuals' support for reducing national debt and reducing deficit spending decreases with age.

Formal economic models often reduce populations to two overlapping generations (an old generation and a young one) and two periods (present and future) for tractability. Yet, it is not clear that preferences for debt reduction are consistent with a binary or linear conception of age in practice; such models provide results that are oversimplified at best and distorted at worst.

The very old and very young voters, given higher discount rates, might be more similar in their preferences for contemporary public goods than these models assume. Above, we have explained that the elderly have an incentive to shift the burden of consolidation on future generations. Young people also face similar incentives to delay. Consider the example of those still in school or just beginning their careers in low wage jobs, who would prefer to borrow today to increase their current welfare and repay debts in the future when they expect to be earning more (Modigliani and Brumberg, 1954). In terms of their relationship with the government, they would prefer to pay taxes later, made possible with borrowing, rather than contemporary taxes. Behavioral research provides evidence for this effect in the context of individual welfare. Falk et al. (2018) show in a cross-national analysis that individuals' patience follows a non-linear form across age, with the young and old demonstrating less elicited patience than do the middle-aged. Jacobs and Matthew (2012) suggest a similar 
logic might be at play in attitudes towards government policy as the very young discount the future more than the middle-aged. However, their study lacks sufficient power to conclusively test the relationship.

An agreement between young and old on preferences for debt may also be driven by higher reliance on public spending than those in middle-age. Workers have always been most likely to experience unemployment early in their careers (Bell and Blanchflower, 2011), and youth unemployment has become a major concern in post-crisis Europe. Absent a current income source, the young are likely to demonstrate a hesitancy to support debt reduction for fear that unemployment or education benefits would be subject to cuts (Busemeyer et al., 2009). Instead, they would prefer additional government spending in the present both to drive job growth and to finance social programs. Considering the similar incentives of the young and old to discount the costs of future fiscal crises and associated austerity, we propose a non-linear relationship between age and preferences for debt consolidation.

Hypothesis 2. Younger individuals' support for reducing national debt and deficit spending increases with age while, among older individuals, support decreases with age.

\section{Research Design}

Our hypotheses posit a relationship between opposition to debt reduction policies and age. Testing this relationship is challenging. There are few existing public opinion surveys that explicitly ask citizens about their preferences for public debt. Fewer sources repeatedly ask about debt or ask an identical question in multiple countries to allow for the identification of age from cohort and period effects (we explain below) or have a sample size large enough to capture sufficient variation among a (currently) small elderly population. Fortunately, the Eurobarometer survey has consistently asked hundreds of thousands of Europeans from 


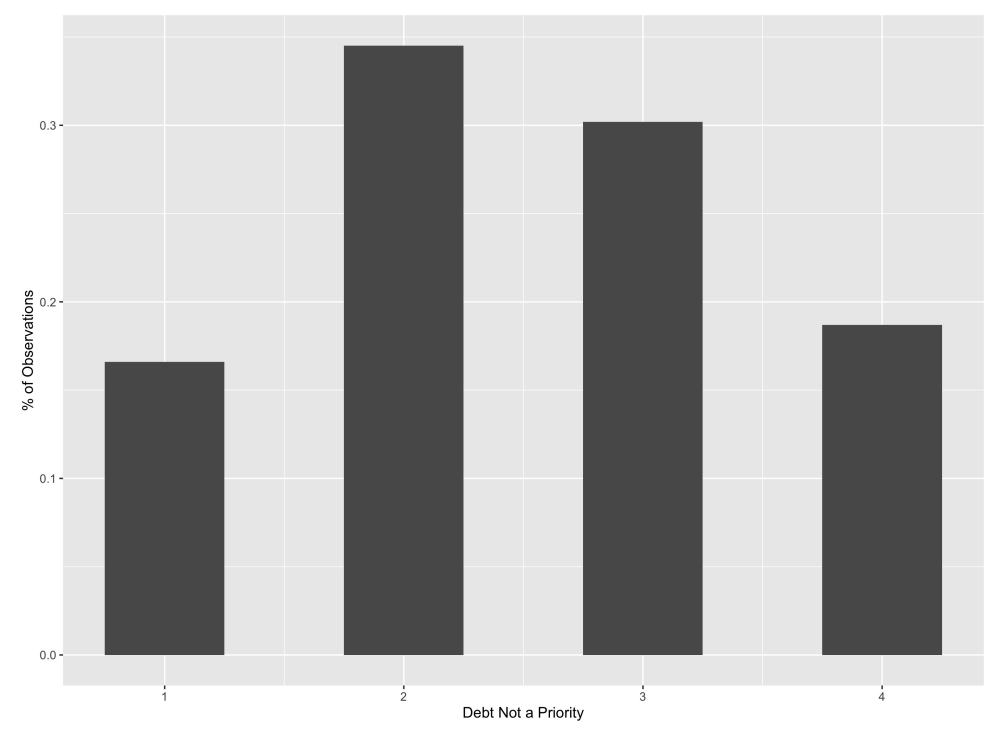

Figure 1: Distribution of Responses to Eurobarometer Question: "Debt Not A Priority" A response of "1" indicates "totally agree" whereas a response of "4" indicates "totally disagree". Note that responses are relatively normally distributed.

28 countries about their attitudes towards debt in their own country in the wake of the European Debt crisis from 2011 to 2019.

The dependent variable in our model is drawn from responses to the following question: "Measures to reduce the public deficit and debt in (OUR COUNTRY) are not a priority for now." Possible responses included "totally agree", "tend to agree", "tend to disagree", "totally disagree" or "don't know". We collapse the dependent variable into a binary variable that indicates if the respondent agrees (totally or tend) with the statement in order to simplify the interpretation of the models. ${ }^{1}$ Figure 1 shows the distribution of this variable in all countries included in the Eurobarometer survey (28 in total).

\footnotetext{
${ }^{1}$ We drop "don't know" answers. The Eurobarometer also asked another question about debt preferences to half of respondents in another branch of the survey. They were asked whether they agree with the statement that "Measures to reduce the public deficit and debt in (OUR COUNTRY) cannot be delayed." We choose not to use this question because it violates standard best practices for survey design, as outlined by both academics and practitioners (Jann and Hinz, 2017; Vannette, 2021). The question is leading in that it presents one option as clearly better than another, and suggests sense of urgency that in many countries may not be warranted. This is reflected in the skewed distribution of the variable in comparison to the question we use. See the Supplementary Appendix for further discussion of the question selection.
} 


\section{Disentangling Age, Period, and Cohort Effects}

Estimating the effect of age on a dependent variable has challenged researchers from a wide variety of disciplines. Age is perfectly correlated with two other potentially salient effects: a potential cohort effect and period effects (referred to as the age-period-cohort effect, or APC). Given a snapshot in time, individuals of a particular age group share a common experience, such as a war, that shapes their attitudes throughout their life. However, simply by comparing individuals across age at a single point in time, it is impossible to identify cohort effects from the effect of aging (Yang and Land, 2016).

Typically, scholars will address such confounding by introducing "controls" for the other factors. As such, it would be intuitive to add controls for birth cohort (year of birth) and the period in which the survey was conducted (year of survey). However, this approach is problematic as age is a function of both cohort and period. The combination of both the period and the cohort perfectly predicts age (age $=$ period - cohort). As such, the variables are co-linear but potentially driven by distinct causal processes. Further, any design to estimate all three is rank deficient (Fosse and Winship, 2019). Fortunately, our data includes 20 waves. To address confounding from period effects, we simply add fixed-effects for each survey wave. Our remaining problem then is addressing cohort and age confounding.

Scholars have developed a variety of strategies to circumvent this identification problem. Each requires a trade-off in the assumptions made in order to estimate any of the three vari-

ables (Bell, 2020; Fosse and Winship, 2019; Stegmueller, 2014). Our paper adopts two such methods in order to demonstrate the robustness of our findings to alternative approaches. This is important because research suggests that results from APC analyses are especially prone to modeling choices to overcome the notorious identification problem (Fosse and Winship, 2019). However, we cannot entirely resolve this problem by controlling for cohort effects since the Eurobarometer survey includes insufficient generational replacement with only ten years of data. As such, the findings are conditional on the strength of these assumptions. 
The first approach is to make a strong assumption that the slope of cohort effects is zero. We defend this by pointing to the cross-national diversity of our sample. Unlike many APC studies that focus on a single country, our sample includes many countries with varied histories. As such, it is unlikely that cohorts across countries will have experienced similar events that shape their attitudes towards government debt simultaneously in a similar way. The second approach is to include theoretically informed controls that capture the mechanisms by which cohort experiences are likely to influence attitudes towards government debt. In our estimation, we control for an individuals' left-right political orientation, their social class, and education. If a cohort experience affects preferences for debt policy it will likely be through political ideology as political leadership during an individual's formative years have a strong impact on their life-long partisan affiliation (Dinas, 2013). Second, if events experienced earlier in life, such as a war or an economic crisis, disrupt your education and income, their impact on preferences is likely to be long-lasting (Alesina and Giuliano, 2011; Giuliano and Spilimbergo, 2014). This will have a strong effect on an individual's ability to weather debt consolidation.

\section{Other Covariates}

Age is an exogenous variable in our analysis given that attitudes towards debt cannot impact the year in which an individual was born. However, we still might have threats to inference if our sample is biased because of differences in life expectancy. To account for this concern, we control for our respondent's gender to reflect the differences in life expectancy between men and women. Similarly, we control for self-reported social-class ${ }^{2}$ and years of education (logged) to address concerns that life expectancy is a product of socioeconomic status in

\footnotetext{
${ }^{2}$ Respondents are asked to identify their social class as "lower," "lower-middle," "middle," "uppermiddle," or "upper." This question is the closest approximation in the Eurobarometer survey for income. Only $0.6 \%$ of respondents identified with the "upper-middle" or "upper" class; this skew may reflect upperclass respondents' desire to be perceived as part of the middle class, as has been the case in other social surveys (Amoranto et al. (2010)).
} 
addition to addressing the age, period, cohort problem we discussed above. ${ }^{3}$

To control for time-invariant differences between countries and to separate age and period effects, we include both country and survey wave fixed effects. An additional concern is that the young tend to be highly mobile, and are more likely to migrate towards urban centers given greater employment and cultural opportunities (Rodden, 2019). This presents the possibility that statistical differences in age might reflect urban-rural political divides. As such, we control for this with a binary rural variable coded from the respondent's assessment of their location.

Lastly, we control for partisan identity for two reasons. First, as we mentioned above, partisan identity is one prominent way in which cohort effects may present themselves. Second,conventional wisdom suggests that individuals become more conservative as they age. There is little evidence to support this claim, and research suggests that people develop stable political attitudes early in life (Peterson et al., 2020), but we still control for the possibility that partisan identity affects debt preferences differently as people age. As such, we include each respondent's self-reported position on a left-right continuum (with 1 representing far-left and 10 representing far-right) in our central analysis.

\section{Estimation}

We use a linear probability model (LPM) to produce our estimates. LPM is an optimal choice given that the bias it generates is minimal, relative to a non-linear model, in this context where the predicted probabilities lie in the middle of the distribution (Horrace and Oaxaca, 2006). The LPM specification also has the advantage, over non-linear models, of easing interpretation of effect while also including several sets of fixed effects that are necessary to address the age-period-cohort issue and the cross-sectional composition of the data. To

\footnotetext{
${ }^{3}$ We further investigate life expectancy in the Supplementary Appendix, where we replace age with an estimate of the individual's remaining years of life. The results are similar to those produced with age.
} 
address concerns over our specification choice, we present several alternative specifications in the Supplementary Appendix including estimates using OLS with the original ordinal variable and a conditional-logit specification.

$$
Y_{i l t}=A g e \beta_{1}+A g e^{2} \beta_{2}+\boldsymbol{W} \boldsymbol{\beta}_{\boldsymbol{i l t}}+\gamma_{l}+\theta_{t}+\epsilon_{i l t}
$$

We estimate the equation above in which $Y_{i l t}$ is our binary outcome $(1=$ agree debt is not a priority) for respondent $i$, in country $l$, at time $t$. $\boldsymbol{W} \boldsymbol{\beta}$ indicates a matrix of control variables and their coefficients. $\gamma$ indicates the country fixed effect and $\theta$ indicates the survey-wave fixed effect, and we employ heteroskedasticity-robust standard errors. ${ }^{4}$ There are two survey waves in each year, generally administered in May and November. ${ }^{5}$

\section{Results}

We first examine the linear relationship between age and support for debt reduction. Figure 2 presents the predicted $\mathrm{Y}$ and $95 \%$ confidence intervals across age when we exclude the squared term. ${ }^{6}$ The figure demonstrates no support for the first hypothesis. As such, we move on to test the non-linear relationship specified in Hypothesis 2.

Figure 3 illustrates the predicted values and marginal effects of age from a linear probability model in which we added the controls we described above and utilized the maximum available sample provided by the Eurobarometer data $(\mathrm{N}=112,689)$. Notably, some waves of the Eurobarometer are dropped from our analysis because the collection of the control

\footnotetext{
${ }^{4}$ We decide not to cluster our standard errors following the recommendations of Abadie et al. (2017). They suggest to cluster only if there is a strong sampling reason (non-random sampling) or an experimental reason (clustered treatment) to do so. The Eurobarometer survey is a random sample of respondents in each country and our treatment of interest, age, is both largely exogenous and clearly assigned at the individual level.

${ }^{5}$ European Commission and European Parliament, Brussels (2019): Eurobarometer 91.5 (2019). Kantar Public, Brussels [producer]. GESIS Data Archive, Cologne. ZA7576 Data file Version 1.0.0

${ }^{6}$ We present the coefficient tables in the Supplementary Appendix for all reported models.
} 


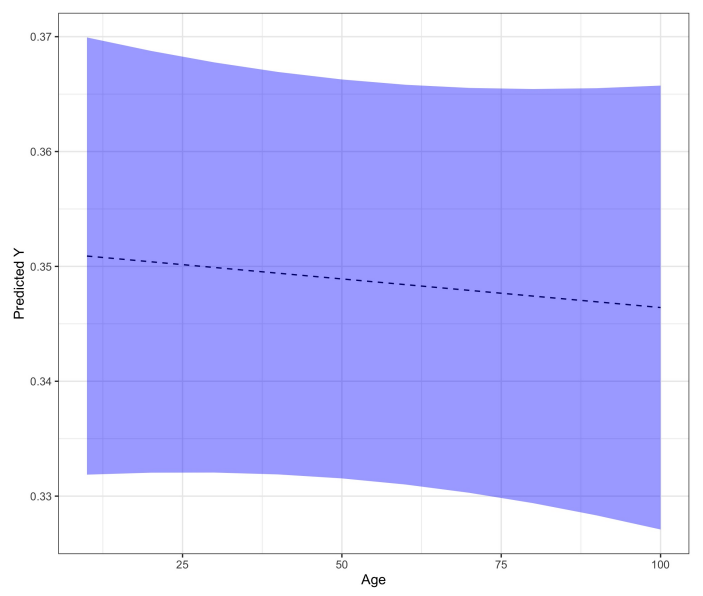

Figure 2: Age and Debt Attitudes: Omitting the Squared Term and including Control Variables The figure indicates the predicted Y across values of Age in a model excluding a squared term for Age. The right panel presents the marginal effect of age across age. The blue shaded area indicates the $95 \%$ confidence interval around the prediction. $\mathrm{N}=112,689$.

variables was not consistent. Our main model includes 11 waves collected every six months between November 2014 and November 2019.

The model supports the non-linear relationship laid out in Hypothesis 2. As individuals approach middle age, they are less likely to agree that reducing the debt and the deficit are not a priority. As Europeans approach the end of their time in the workforce, they are more likely to agree. From the nadir of the prediction at 53 years of age to 100 years, the concern for the debt increases by $6 \%$. The sample size decreases rapidly as individuals approach 100 years of age, as shown in the right plot, emphasizing the need for a very large sample to examine the voting behavior of the elderly. The results from our pooled model are thus relatively modest, substantively important but not as deterministic as has been portrayed by the models we mentioned above. The effect of age is more comparable to that of the respondent's residence in an urban or rural area; a one-standard deviation increase in age decreases debt concern by $0.9 \%$, while living in an urban area decreases debt concern by $1.3 \%$ compared to living in a rural area.

Figure 4 replicates the analysis presented in Figure 3 but excludes the control variables 

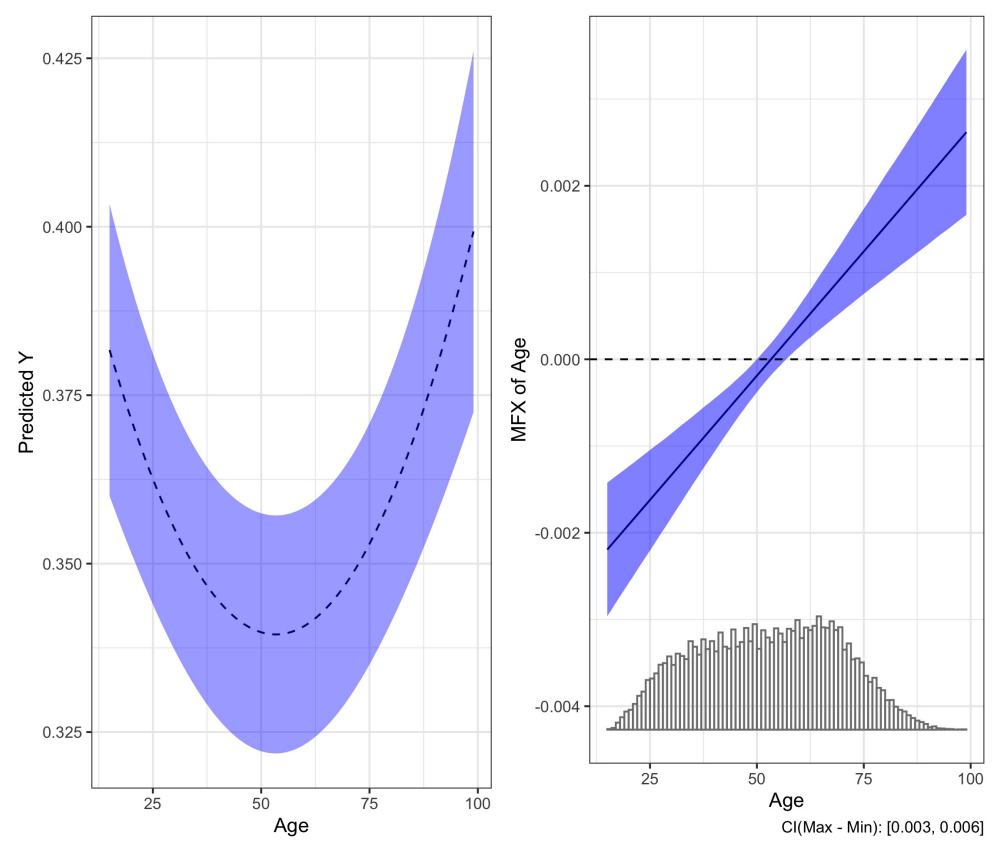

Figure 3: Age and Debt Attitudes Including Control Variables The left panel indicates the predicted Y across values of Age. The right panel presents the marginal effect of age across age. In both panels, the blue shaded area indicates the $95 \%$ confidence intervals. $\mathrm{N}=112,689$.

to make use of the entire Eurobarometer sample. The relationship is similar though the effect of age among the young is somewhat diminished.

\section{Disaggregating Effects by Wave and Country}

How universal is this non-linear effect of age on debt preferences? We further investigate this result by estimating each survey wave and country individually. A difference in the effect of age across the waves of our sample might indicate that cohort effects, despite our best efforts to control for them, are responsible for the relationship we observe with age. Figure 5 presents the estimated marginal effect when we run our model on each survey wave (labeled A and B for each year). First, it is notable that there is significant variation in the marginal effect across different waves. However, an overwhelming majority of models have the same non-linear effect we present in the figures above. While there is variation, the variation in the 

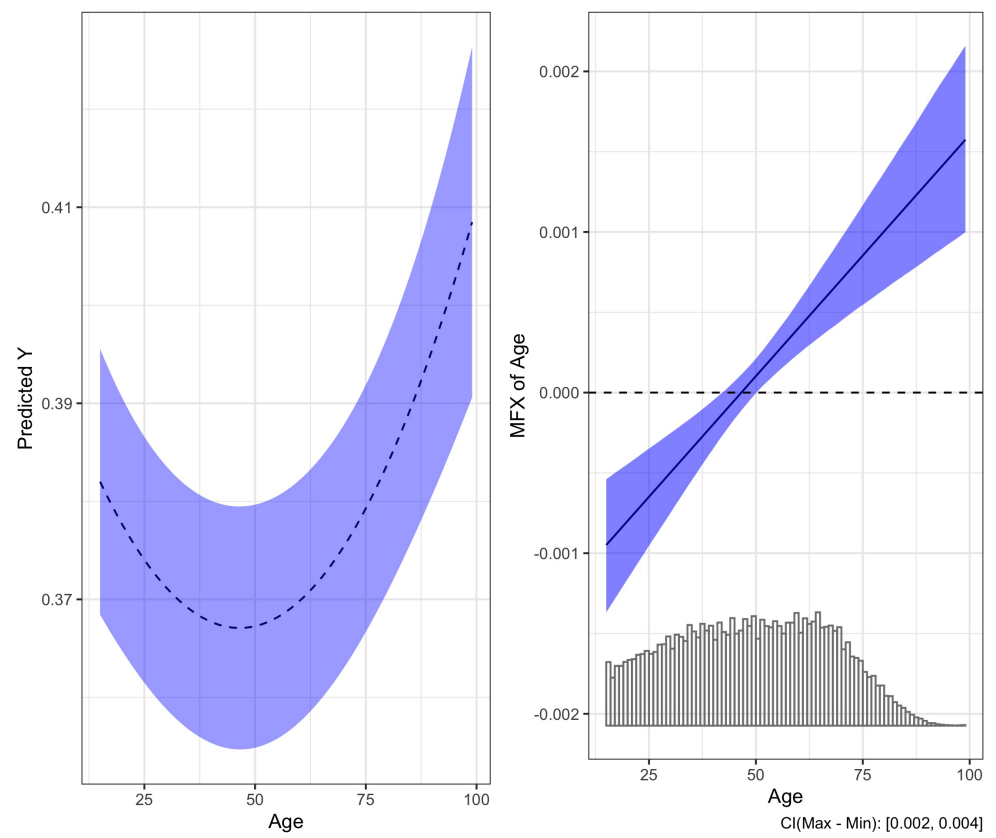

Figure 4: Age and Debt Attitudes Excluding Control Variables The left panel indicates the predicted Y across values of Age. The right panel presents the marginal effect of age across age. In both panels, the blue shaded area indicates the $95 \%$ confidence intervals. $\mathrm{N}=255,086$.

marginal effect does not appear to follow a temporally consistent pattern. While the results suggest that we should temper our assessment of the effect of age, it does not indicate that there is a clear cohort difference. Still, this is not a definitive test as there is little cohort replacement within the 10-years of surveys.

There is also significant heterogeneity in marginal effects between countries, and less agreement in the direction of the effect of age. Figure 6 presents the estimated marginal effect of age by country, with countries split between panels by the sign of their marginal effect. Most countries have the convex non-linear relationship shown in the pooled model, but a significant number have the opposite effect. Age clearly influences preferences very differently across European states, suggesting that other factors moderate this relationship.

What drives this cross-national heterogeneity? From the rational perspective of elderly and very young voters, opposition to debt consolidation is borne out of a concern that social 


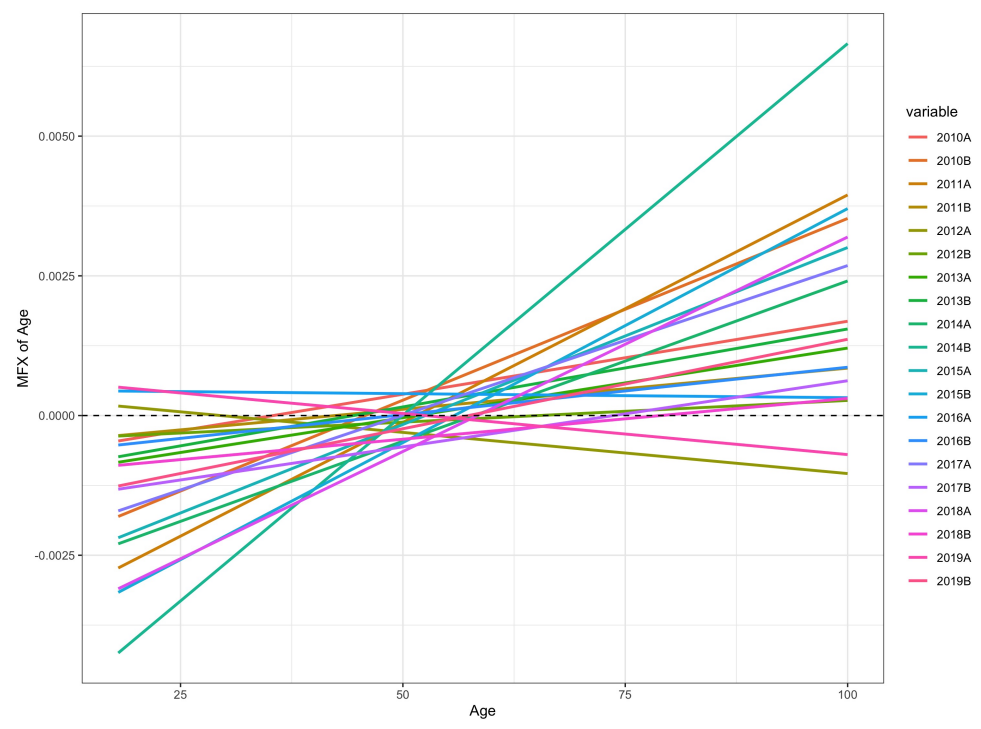

Figure 5: Marginal Effect of Age by Survey Wave. While there is significant variation in the marginal effect of different survey waves, they largely follow the same non-linear effect and do not appear to demonstrate a temporally consistent pattern.

programs designed to redistribute wealth or income will be cut. Yet, there are significant differences in the generosity of social welfare within the European Union and the dependence of individuals on those programs. It stands to reason that those voters that are more dependent on government transfers have more of an incentive to delay debt consolidation, as we expect individuals to recognize the strong relationship between debt consolidation and reductions in government spending. Where social programs are generous, elderly are more reliant on pensions, whereas elderly in countries with more limited programs depend more on private savings during retirement (Disney, 2000). Those living in countries that direct significant resources towards the elderly should observe a stronger relationship between age and support for debt reduction, as they stand to lose the most from debt-consolidation. Younger people are more heavily reliant on welfare programs that provide unemployment and education benefits (Busemeyer et al., 2009), and may be comparably sensitive to debt reduction at the cost of these programs. The young and the old are similar in their reliance on social spending, and so their preferences for debt reduction may be similarly strengthened 

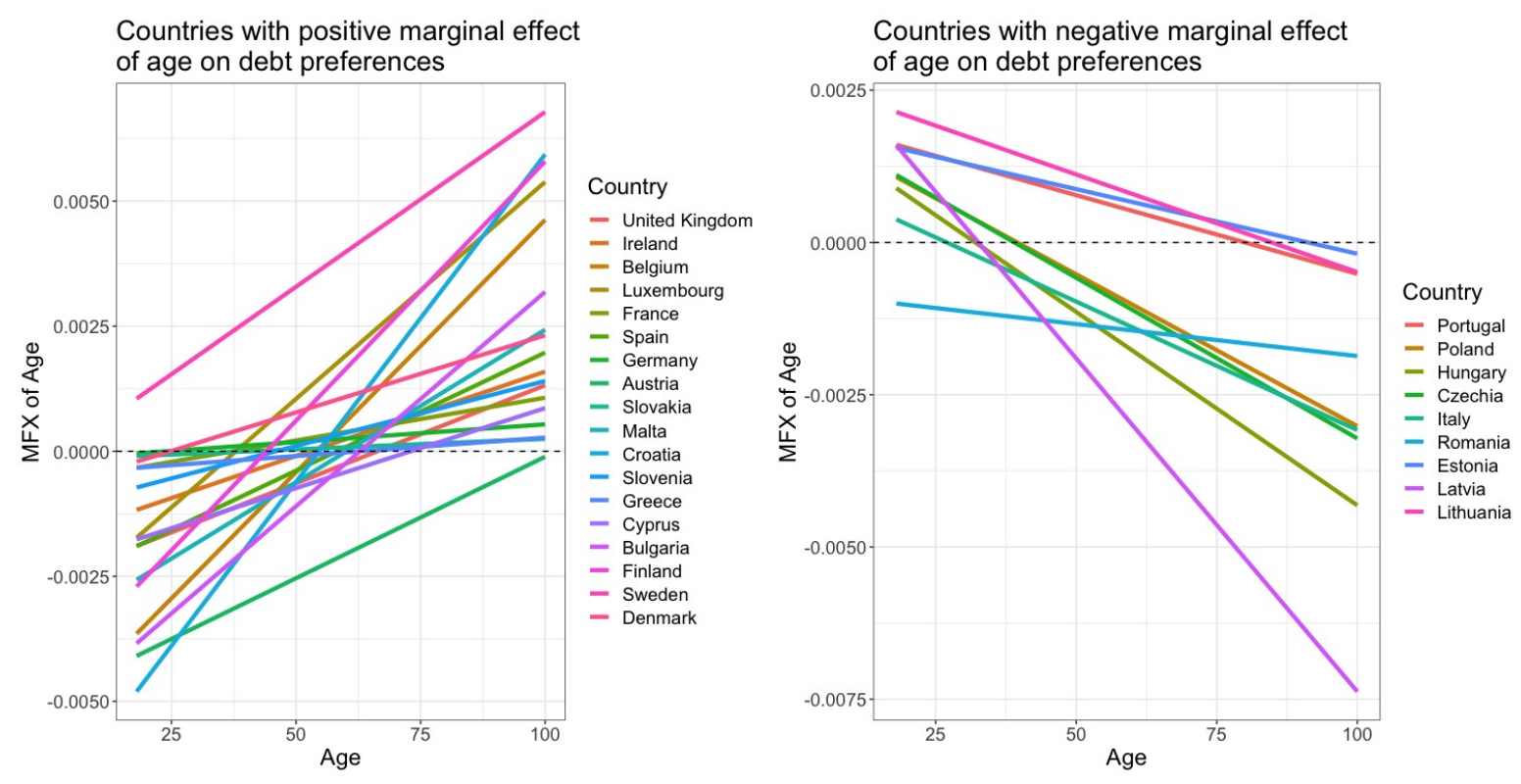

Figure 6: Marginal Effect of Age by Country. Countries where the marginal effect of age is positive are shown on the left; countries where the marginal effect of age is negative are shown on the right.

when generous welfare programs are at stake.

To test the moderating effect of welfare generosity, we interact age and its squared term first with average pension spending per pensioner and then with social spending per capita. ${ }^{7}$ We use data from the Eurostat Employment and Social Inclusion Indicators database to measure these variables. ${ }^{8}$

We estimate the following equation to capture the marginal effect of the quadratic form across these two moderating variables represented by $\mathrm{Z}$ in the equation:

$$
Y_{i l t}=A g e \beta_{1}+A g e^{2} \beta_{2}+Z \beta_{3}+(A g e * Z) \beta_{4}+\left(A g e^{2} * Z\right) \beta_{5}+\boldsymbol{W} \boldsymbol{\beta}+\gamma_{l}+\theta_{t}+\epsilon_{i l t}
$$

Figure 7 graphs the predicted outcome by welfare system generosity. The left-hand panel shows the predicted $Y$ when holding pension spending per pensioner at one standard devia-

\footnotetext{
${ }^{7}$ Ideally, we would measure dependence on the welfare system at the individual level, and investigate the moderating effect of dependence on the relationship between age and debt. As the Eurobarometer does not ask respondents about their wealth, income, or use of welfare services, our analysis is limited to the effect of the respondent's national welfare environment on their debt preferences.

${ }^{8}$ European Commission: Eurostat, Brussels (2021): European System of Integrated Social Protection Statistics. spr_exp_pens Data file Version v3.7.1
} 
tion above the mean (blue) and one standard deviation below the mean (gray). Consistent with our expectations, we find that age is only relevant where pension spending is already generous. Assuming that people make plans for retirement given existing pension arrangements, this suggests that age has a salient effect on attitudes towards debt reduction when individuals are dependent on the state for their retirement.

Next, we replicate this analysis with broad social welfare spending (not solely that for pensioners) and find a similar relationship. The right-hand panel of Figure 7 presents the predicted values when we hold public spending over GDP at one standard deviation above and below the mean. Again, we see the relationship with age is most prominent in those states with high public spending and less pronounced where social spending represents a smaller fraction of the economy.

The panels in Figure 7 indicate the substantive effect of age is larger among countries with more generous social and pension spending. Our models suggest that the conditioning effect of general public spending is relatively larger than pension spending alone, with a substantial difference between high and low public spending countries. We do note however, that generous pension and public spending is potentially confounded by other variables. In particular, the legacy of communism might be influencing both spending levels and attitudes towards debt. We address this concern by providing additional models in the Supplementary Appendix that directly address confounding with and interaction between communist legacy and our age terms. The conditioning effects of pension and social spending are diminished but still emerges as an important conditioning variable. 

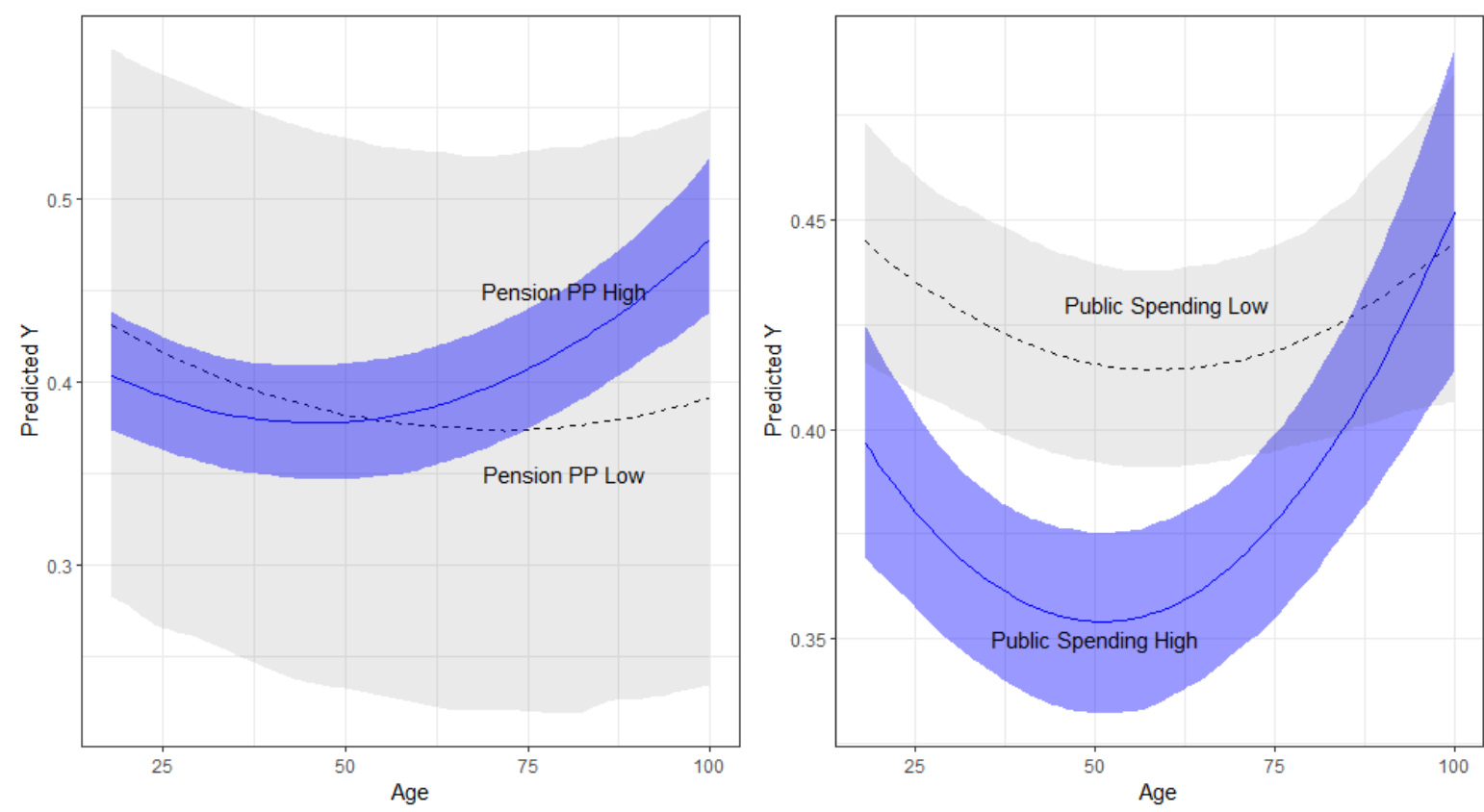

Figure 7: Predicted $\mathbf{Y}$ across age by welfare system generosity Left panel shows predicted $\mathrm{Y}$ in countries with high (blue) and low (gray) Pension Spending per Pensioner. Right panel shows predicted $\mathrm{Y}$ in countries with high (blue) and low (gray) public spending. In each case 'high' and 'low' are defined as 1 standard deviation above and below the mean values for country-years in our sample, respectively. The shaded areas indicate the $95 \%$ confidence intervals around the predictions generated from simulations of variance and covariance matrices.

\section{Conclusion}

This paper has investigated the role of age in shaping preferences for deficit spending and the management of public debt. Although age is assumed to be a central explanatory variable in theoretical models of sovereign debt accumulation and stabilization delay, that assumption has not been systematically tested. Here, we find a non-linear relationship between age and preferences regarding debt. Support for debt reduction grows as respondents move out of young adulthood and into middle age, their prime earning years, and begins to decrease as they enter retirement. The results are robust to a variety of different model specifications and alternative measures to age (life expectancy).

While our findings appear to add support to existing theoretical models, the substantive 
effect of age is modest and the relationship varies across countries, suggesting the importance of national context. We demonstrate that the non-linear age effect is strongest in countries with more generous social programs, suggesting that old and young are most supportive of debt when they would stand to lose the most from debt reduction.

Future work should test the effects in non-EU countries and, if possible, test a wider range of data in order to attempt to further disentangle the effect of age from period and cohort effects. Data limitations also prevent an examination of the effect of individual welfare dependence on fiscal preferences, which may be a valuable topic for further research.

Our findings shed new light on a core variable in the study of the management of public debt, and indicate that conventional models misrepresent the effect of age with a linear relationship to fiscal preferences. The intergenerational conflict narrative commonly discussed in the literature incorrectly pits the old against the young, when their preferences for public spending are in fact quite similar. We address a question that will become increasingly important as debt burdens rise and public spending shifts towards growing elderly populations in the European Union and around the world. As voting populations age, the preferences of the elderly will become increasingly important for policy decisions. Our analysis shows that the future of fiscal politics is not one of intergenerational conflict, but rather pressure for growing debt burdens from young and old voters alike. 


\section{References}

Abadie, Alberto , Susan Athey, Guido W Imbens, and Jeffrey Wooldridge (2017). When should you adjust standard errors for clustering? Technical report, National Bureau of Economic Research.

Acemoglu, Daron and Pierre Yared (2010, May). Political limits to globalization. American Economic Review 100(2), 83-88.

Alesina, Alberto and Paola Giuliano (2011). Preferences for redistribution. In Handbook of social economics, Volume 1, pp. 93-131. Elsevier.

Amoranto, Glenita, Natalie Chun, and Anil B Deolalikar (2010). Who are the middle class and what values do they hold? evidence from the world values survey. Evidence from the World Values Survey (October 1, 2010). Asian Development Bank Economics Working Paper Series (229).

Andersen, Steffen, Glenn W. Harrison, Morten Igel Laue, and E. Elisabet Rutsrom (2006). Elictation using multiple price list formats. Experimental Economics 9(4), 383-405.

Andersen, Torben M (2019). Intergenerational conflict and public sector size and structure: A rationale for debt limits? European Journal of Political Economy 5\%, 70-88.

Andor, Mark A , Christoph M Schmidt, and Stephan Sommer (2018). Climate change, population ageing and public spending: evidence on individual preferences. Ecological economics 151, 173-183.

Bansak, Kirk , Michael M. Bechtel, and Yotam Margalit (2020). Why austerity? the mass politics of a contested policy. SSRN.

Barnes, Lucy and Tim Hicks (2018). Making austerity popular: The media and mass attitudes towards fiscal policy. American Journal of Political Science 62(2), 340-354.

Barnes, Lucy and Timothy Hicks (2021). All keynesians now? public support for countercyclical government borrowing. Political Science Research and Methods 9(1), 180-188.

Basso, Henrique S and Omar Rachedi (2018). The young, the old, and the government: demographics and fiscal multipliers.

Bell, Andrew (2020). Age period cohort analysis: a review of what we should and shouldn't do. Annals of Human Biology 47(2), 208-217.

Bell, David NF and David G Blanchflower (2011). Youth unemployment in europe and the united states. Nordic Economic Policy Review 1(2011), 11-37.

Bisin, Alberto , Alessandro Lizzeri, and Leeat Yariv (2015). Government policy with time inconsistent voters. The American Economic Review 105(6), 1711-1737. 
Bogetic, Zeljko, Harun Onder, Anil Onal, Emilia Skrok, Anita Schwartz, and Hernan Winkler (2015). Fiscal policy issues in the aging societies. Discussion Paper: MFM Global Practice 1(95266).

Bohr, Jeremiah (2017). Is it hot in here or is it just me? temperature anomalies and political polarization over global warming in the american public. Climatic Change 142(1), 271285.

Bonoli, Giuliano and Silja Häusermann (2009). Who wants what from the welfare state? socio-structural cleavages in distributional politics: Evidence from swiss referendum votes. European societies 11(2), 211-232.

Busemeyer, Marius R, Achim Goerres, and Simon Weschle (2009). Attitudes towards redistributive spending in an era of demographic ageing: the rival pressures from age and income in 14 oecd countries. Journal of European Social Policy 19(3), 195-212.

Cattaneo, M Alejandra and Stefan C Wolter (2009). Are the elderly a threat to educational expenditures? European Journal of Political Economy 25(2), 225-236.

Cukierman, Alex and Allan H Meltzer (1989). A political theory of government debt and deficits in a neo-ricardian framework. The American Economic Review, 713-732.

Curtis, K. Amber, Joseph Jupille, and David Leblang (2015). Iceland on the rocks: The mass political economy of sovereign debt resettlement. International Organization forthcoming.

Diamond, Peter A. (1965). National debt in a neoclassical growth model. The American Economic Review Vol. 55, No. 5, Part 1, 1126-1150.

Dinas, Elias (2013). Opening "openness to change" political events and the increased sensitivity of young adults. Political Research Quarterly 66(4), 868-882.

Disney, Richard (2000). Declining public pensions in an era of demographic ageing: Will private provision fill the gap? European Economic Review 44(4-6), 957-973.

Emery, Thomas (2012). Intergenerational conflict: evidence from europe. Journal of Population Ageing 5(1), 7-22.

Esarey, Justin and Jane Lawrence Sumner (2018). Marginal effects in interaction models: Determining and controlling the false positive rate. Comparative Political Studies 51 (9), $1144-1176$.

Eurostat (2021). Life expectancy by age and sex, file: Demo_mlexpc_v3.7.1202104195867estat_linux_prod.

Falk, Armin , Anke Becker, Thomas Dohmen, Benjamin Enke, David Huffman, and Uwe Sunde (2018). Global evidence on economic preferences. The Quarterly Journal of Economics 133(4). 
Fosse, Ethan and Christopher Winship (2019). Analyzing age-period-cohort data: A review and critique. Annual Review of Sociology 45, 467-492.

Fuest, Clemens and Daniel Gros (2019). Government debt in times of low interest rates: the case of europe. Technical report, EconPol Policy Brief.

Giuliano, Paola and Antonio Spilimbergo (2014). Growing up in a recession. Review of Economic Studies 81(2), 787-817.

Goerres, Achim (2007). Why are older people more likely to vote? the impact of ageing on electoral turnout in europe. The British Journal of Politics and International Relations $9(1), 90-121$.

Goerres, Achim (2009). The political participation of older people in europe. The Greying of Our Democracies 81, 80 .

Goerres, Achim and Markus Tepe (2010). Age-based self-interest, intergenerational solidarity and the welfare state: A comparative analysis of older people's attitudes towards public childcare in 12 oecd countries. European Journal of Political Research 49(6), 818-851.

Grasso, Maria Teresa, Stephen Farrall, Emily Gray, Colin Hay, and Will Jennings (2019). Thatcher's children, blair's babies, political socialization and trickle-down value change: An age, period and cohort analysis. British Journal of Political Science 49(1), 17-36.

Harper, Sarah (2014). Economic and social implications of aging societies. Science $346(6209), 587-591$.

Hatemi, Peter K , Carolyn L Funk, Sarah E Medland, Hermine M Maes, Judy L Silberg, Nicholas G Martin, and Lindon J Eaves (2009). Genetic and environmental transmission of political attitudes over a life time. The Journal of Politics 71 (3), 1141-1156.

Hersch, Joni and W Kip Viscusi (2006). The generational divide in support for environmental policies: European evidence. Climatic Change $77(1), 121-136$.

Horrace, William C and Ronald L Oaxaca (2006). Results on the bias and inconsistency of ordinary least squares for the linear probability model. Economics Letters 90(3), 321-327.

Huddy, Leonie , Jeffrey M Jones, and Richard E Chard (2001). Compassionate politics: Support for old-age programs among the non elderly. Political Psychology 22(3), 443-471.

Jacobs, Alan M. and J. Scott Matthew (2012). Why do citizens discount the future? public opinion and the timing of policy consequences. British Journal of Political Science 42(4), 903-935.

Jann, Ben and Thomas Hinz (2017). Research question and design for survey research. In: The SAGE Handbook of Survey Methodology Chapter 16. 
Lee, Ronald (2016). Macroeconomics, aging, and growth. In Handbook of the economics of population aging, Volume 1, pp. 59-118. Elsevier.

Magistretti, Giacomo (2019). Fiscal sustainability in aging economies.

Mankiw, N.G. and Douglas Elmendorf (1999). Government Debt. North Holland.

Modigliani, Franco and Richard Brumberg (1954). Utility analysis and the consumption function: An interpretation of cross-section data. Franco Modigliani 1(1), 388-436.

Naumann, Elias (2018). Increasing conflict in times of retrenchment? attitudes towards healthcare provision in europe between 1996 and 2002. In Welfare State Reforms Seen from Below, pp. 245-271. Springer.

Nelson, Stephen C and David A Steinberg (2018). Default positions: What shapes public attitudes about international debt disputes? International Studies Quarterly 62(3), 520533.

O'Grady, Tom (2018). Careerists versus coal-miners: Welfare reforms and the substantive representation of social groups in the british labour party. Comparative Political Studies 52 (4).

O'Grady, Tom (2020). Is europe becoming a 'gerontocracy'? new evidence on age cleavages in europe since the 1980s. Unpublished Working Paper ), 23-40.

Pench, Lucio (2020). The 2021 ageing report. European Economy Institutional Papers 142.

Peterson, Johnathan C , Kevin B Smith, and John R Hibbing (2020). Do people really become more conservative as they age? The Journal of Politics 82(2), 600-611.

Prior, Markus (2010). You've either got it or you don't? the stability of political interest over the life cycle. The Journal of Politics 72(3), 747-766.

Rodden, Jonathan A. (2019). Why Cities Lose: The Deep Roots of the Urban-Rural Political Divide. New York, NY: Basic Books.

Sinn, Hans-Werner and Silke Uebelmesser (2003). Pensions and the path to gerontocracy in germany. European Journal of Political Economy 19(1), 153-158.

Song, Zheng, Kjetil Storesletten, and Fabrizio Zilibotti (2012). Rotten parents and disciplined children: A politico-economic theory of public expenditure and debt. Econometrica $80(6), 2785-2803$.

Sørensen, Rune J (2013). Does aging affect preferences for welfare spending? a study of peoples' spending preferences in 22 countries, 1985-2006. European Journal of Political Economy 29, 259-271. 
Stegmueller, Daniel (2014). Bayesian hierarchical age-period-cohort models with timestructured effects: An application to religious voting in the us, 1972-2008. Electoral Studies 33, 52-62.

Tabellini, Guido (1991). The politics of intergenerational redistribution. Journal of Political Economy 99(2), 335-357.

Vannette, David L. (2021). The qualtrics handbook of question design. Qualtrics.

Yang, Yang and Kenneth C Land (2016). Age-Period-Cohort Analysis: New Models, Methods, and Empirical Applications. CRC Press.

Yared, Pierre (2019). Rising government debt: Causes and solutions for a decades-old trend. Journal of Economic Perspectives 33(2), 115-40.

Yoshino, Naoyuki, Chul Ju Kim, and Pitchaya Sirivunnabood (2019). Aging population and its impacts on fiscal sustainability. Aging SocietieS. 


\section{Supplementary Appendix}

\section{A. Alternative model specifications}

To validate the decision to use a binary outcome variable in an OLS regression, we run our main models using an ordered-logit estimator and an OLS regression with a continuous outcome variable. Both alternative specifications yield similar results, suggesting that our findings do not depend on the construction of the dependent variable.

Figure A..1 compares our main results using a linear probability model with results using all four response levels as a continuous measure, and results using an ordinal logit estimator. The estimated marginal effect is robust to these different specifications, and all support the non-linear relationship between age and preferences for debt.

Next, we check for overconfidence in our estimated interaction effects due to the multiple comparison problem. Estimating the marginal effect of $X$ on $Y$ conditional on $Z$ using a standard t-test can produce erroneous statistically significant results as the test is run repeatedly for every value of $X$ and $Z$. We follow recommendations in Esarey and Sumner (2018) to adjust confidence intervals to account for potential false positives. Figure A..2 shows the marginal effect of age with standard confidence intervals and those adjusted to control the false discovery rate (FDR); adjustment for false-positives does not change our results. 
Linear Probability Model (Main results)
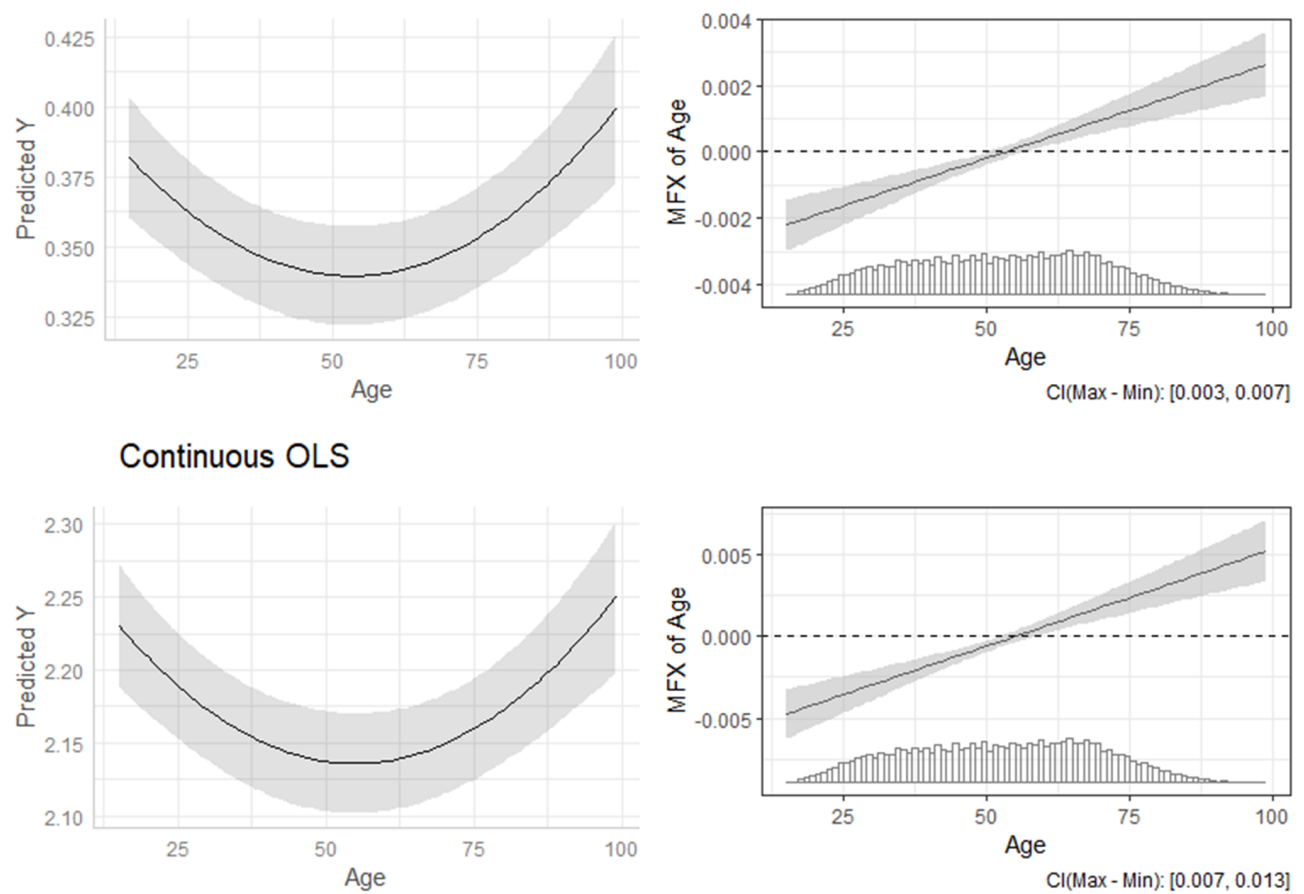

Ordinal Logit

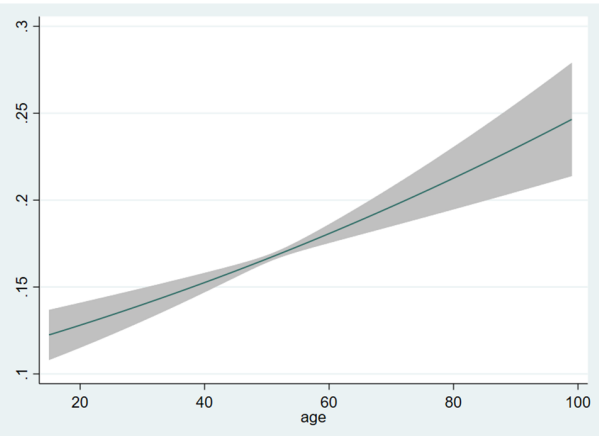

Figure A..1: The Effect of Age with Controls. The top two panels represent the results using all four levels of the survey question as a continuous outcome variable. The middle two panels represent the results when the outcome variable is re-coded as binary. The bottom panel represents the results using an ordinal logit specification. Number of observations: 112,689 . 


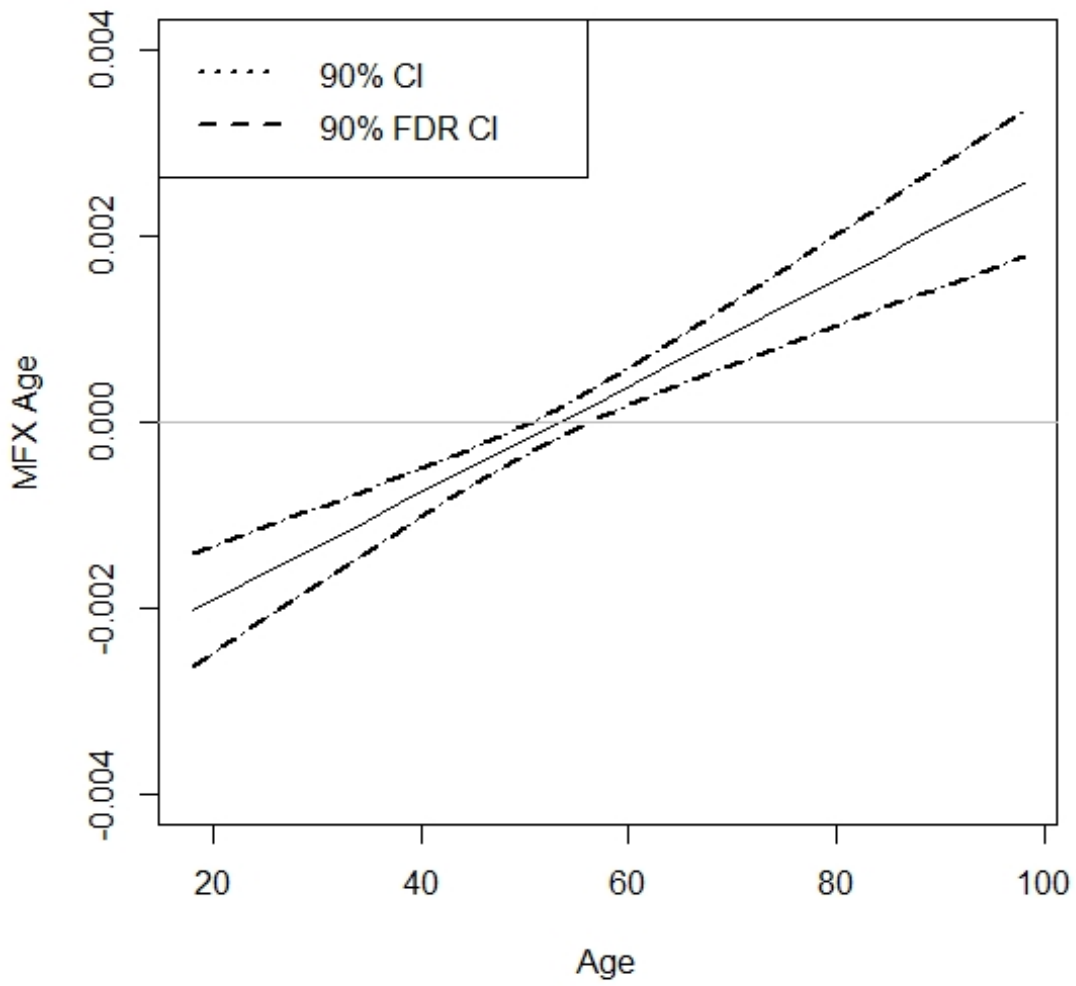

Figure A..2: The Effect of Age with False Discovery Rate-robust confidence intervals. Number of observations: 112,689 . 


\section{B. Choice of survey question}

The Eurobarometer survey includes two questions that capture preferences for debt. Respondents were randomly assigned to answer only one of the two questions, which are:

1. "Measures to reduce the public deficit and debt in (OUR COUNTRY) are not a priority for now."

2. "Measures to reduce the public deficit and debt in (OUR COUNTRY) cannot be delayed."

We use the first question and exclude the latter, as for reasons discussed above, we argue that the phrase "cannot be delayed" could provoke skewed responses because of the implied urgency of the problem, and not accurately capture a valid measure of the individual's debt preferences. Other work by Barnes and Hicks (2021) has combined the two questions to make use of a larger sample when investigating debt preferences in one country, but we believe that this is inappropriate when looking at the entire EU. If both questions captured the same aspect of debt, the distribution of responses for the questions should mirror each other; respondents who strongly disagree with question 1 would be expected to strongly agree with question 2, if they had been asked both. As shown in Figure B..3, this is not the case, and question 2 is left-skewed in the full sample (meaning a high frequency of "strongly agree" responses).
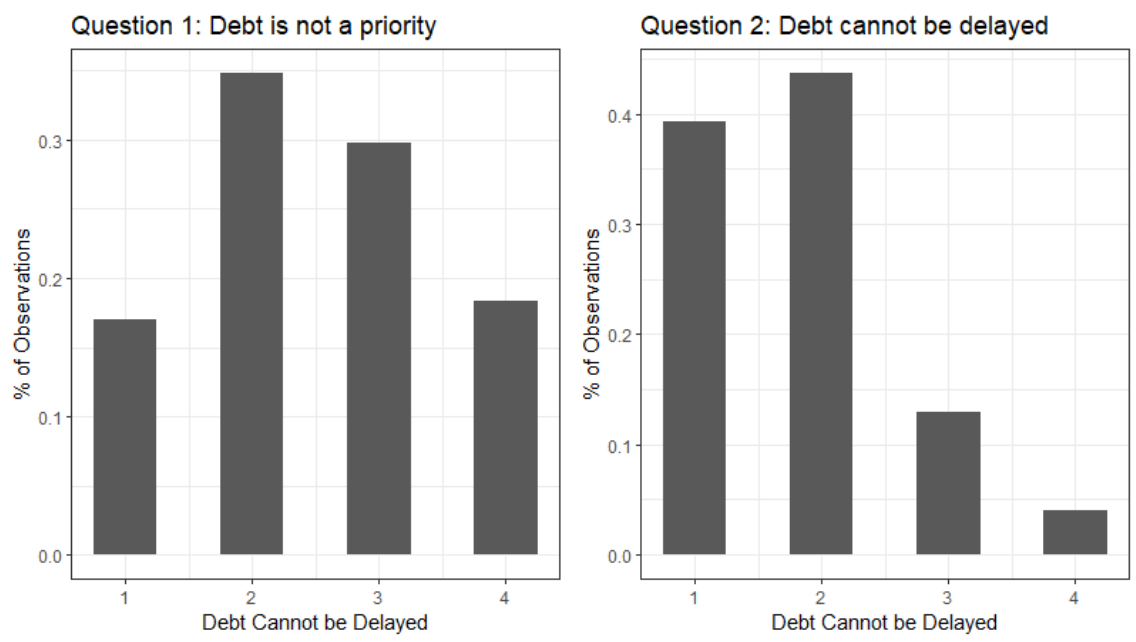

Figure B..3: Distribution of responses to Eurobarometer debt questions. $1=$ "Strongly Agree," 4 = "Strongly Disagree"

When we disaggregate responses by country and survey wave, it is apparent that the skewed distribution of question 2 is not driven by outlier countries or time periods: the high frequency of "strongly agree" responses is persistent across the sample. The two questions clearly measure different effects, so we must choose one to capture debt preferences. Question 1 is a logical choice simply because its distribution is closer to normal, but we validate this 
choice by comparing the distribution of responses with those from other questions designed to capture debt preferences. 


\section{Alternative Measure of Age}

While we treat age as largely exogenous in our main specification, a respondent's life expectancy is not. A longer life expectancy could change preferences for debt if the respondent anticipates living long enough to experience the costs of debt reduction. We test this effect by substituting age with a measure of remaining life expectancy, which is the average remaining life expectancy by gender and age in respondent's country (Eurostat, 2021).
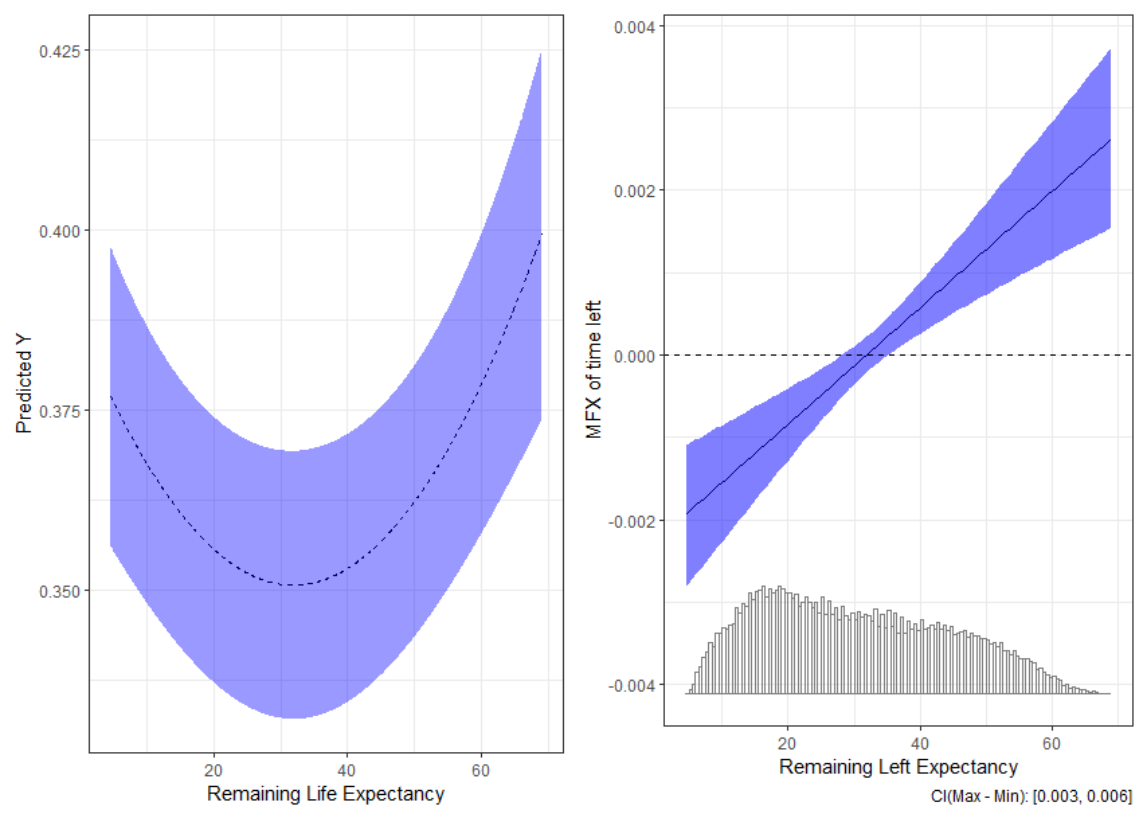

Figure C..4: The Effect of "Remaining Life Expectancy". The left panel shows the predicted $\mathrm{Y}$ across the gap between age and life expectancy. The right panel shows the marginal effect of "time left" across "time left." Number of observations: 105,954.

The results are not substantially different using this relative measure of age. The nonlinear relationship persists, and those with the longest remaining lifespan (young respondents) and those with a short lifespan (older respondents who are approaching their life expectancy) are more likely to agree that debt is not a priority. 


\section{Coefficient Tables}

The main results of this paper are presented in Figures 3, 7. This section presents the underlying regressions. All three regressions include country and year fixed effects and robust standard errors.

1. Figure 3 presents the effect of age on preferences for debt and is based on column 1 of Table D..1.

2. Figure 7 presents both the interaction effect of age and pension spending per capita (based on column 2 of Table D..1) and the interaction effect of age and total public spending (based on column 3 of Table D..1). 
Table D..1: Full Results

\begin{tabular}{|c|c|c|c|}
\hline & \multicolumn{3}{|c|}{ Dependent variable: } \\
\hline & \multicolumn{3}{|c|}{ Debt reduction not priority } \\
\hline & $(1)$ & $(2)$ & $(3)$ \\
\hline Age & $\begin{array}{c}-0.003^{* * *} \\
(0.001)\end{array}$ & $\begin{array}{c}-0.003^{* *} \\
(0.001)\end{array}$ & $\begin{array}{c}0.003 \\
(0.004)\end{array}$ \\
\hline Age squared & $\begin{array}{c}0.00003^{* * *} \\
(0.00001)\end{array}$ & $\begin{array}{c}0.00002 \\
(0.00001)\end{array}$ & $\begin{array}{l}-0.00004 \\
(0.00003)\end{array}$ \\
\hline Pension spending per capita & & $\begin{array}{l}-0.00001 \\
(0.00003)\end{array}$ & \\
\hline Public spending, \%GDP & & & $\begin{array}{l}-0.002 \\
(0.002)\end{array}$ \\
\hline Female & $\begin{array}{c}0.011^{* * *} \\
(0.003)\end{array}$ & $\begin{array}{c}0.013^{* * *} \\
(0.003)\end{array}$ & $\begin{array}{c}0.011^{* * *} \\
(0.003)\end{array}$ \\
\hline Social class & $\begin{array}{c}0.011^{* * *} \\
(0.002)\end{array}$ & $\begin{array}{c}0.012^{* * *} \\
(0.002)\end{array}$ & $\begin{array}{c}0.011^{* * *} \\
(0.002)\end{array}$ \\
\hline Years of education $(\log )$ & $\begin{array}{c}-0.024^{* * *} \\
(0.007)\end{array}$ & $\begin{array}{c}-0.028^{* * *} \\
(0.008)\end{array}$ & $\begin{array}{c}-0.024^{* * *} \\
(0.007)\end{array}$ \\
\hline Left-right scale & $\begin{array}{c}-0.006^{* * *} \\
(0.001)\end{array}$ & $\begin{array}{c}-0.007^{* * *} \\
(0.001)\end{array}$ & $\begin{array}{c}-0.006^{* * *} \\
(0.001)\end{array}$ \\
\hline Rural dummy & $\begin{array}{c}0.013^{* * *} \\
(0.004)\end{array}$ & $\begin{array}{c}0.011^{* * *} \\
(0.004)\end{array}$ & $\begin{array}{c}0.013^{* * *} \\
(0.004)\end{array}$ \\
\hline Urban dummy & $\begin{array}{c}0.026^{* * *} \\
(0.004)\end{array}$ & $\begin{array}{c}0.023^{* * *} \\
(0.004)\end{array}$ & $\begin{array}{c}0.027^{* * *} \\
(0.004)\end{array}$ \\
\hline Age $\mathrm{x}$ Pension spending per capita & & $\begin{array}{r}-0.00000 \\
(0.00000)\end{array}$ & \\
\hline Age squared x Pension spending per capita & & $\begin{array}{c}0.000 \\
(0.000)\end{array}$ & \\
\hline Age x Public spending & & & $\begin{array}{c}-0.0001^{*} \\
(0.0001)\end{array}$ \\
\hline Age squared x Public spending & & & $\begin{array}{l}0.00000^{* *} \\
(0.00000)\end{array}$ \\
\hline Observations & 112,689 & 93,078 & 111,614 \\
\hline
\end{tabular}




\section{E. Confounding by Communism Legacy}

In our analysis, we demonstrated the non-linear effect of age on preferences for debt reduction was conditional on both pension spending and social spending. As we noted, the conditioning effect of these two variables maybe confounded by communist legacy. the former communist states have lower average pension and general social spending. We address this concern here by presenting models in which we address confounding by including in our conditional models an interaction of communist legacy dummy and our age terms. Since the communist dummy drops, we include simpley the interactions between age and the communist dummy and $a g e^{2}$ and the communist dummy. In Figures E..5 and E..6, we present the marginal effects of age at both one standard deviation above and below for both pension spending per capita and social spending as a percentage of GDP. While the marginal effect is somewhat diminished, the effect remains significant for pension and public spending 1SD above the mean and insignificant 1SD below the mean.

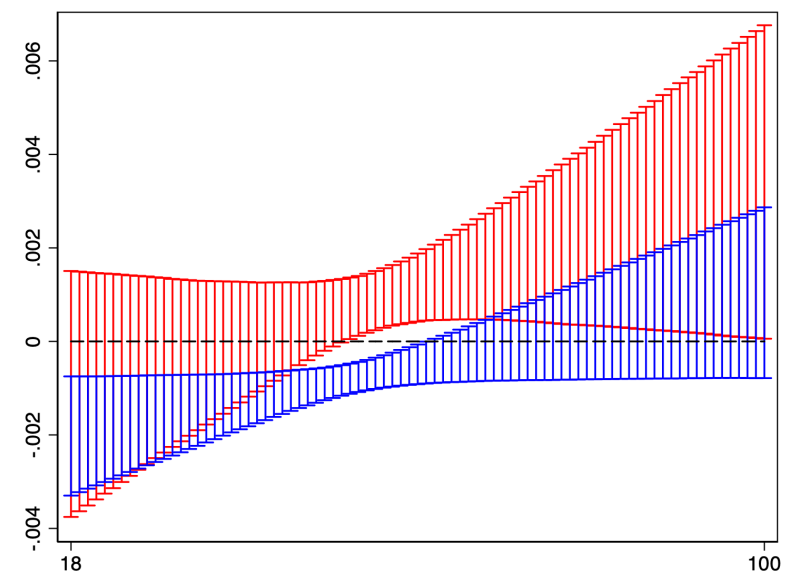

Figure E..5: Marginal Effect of Age at Different Levels of Pensions Spending Per Capita. The graph presents the marginal effect of age across age. The effects were generated via simulation utilizing 1000 draws of the variance and co-variance matrices. The red and blue bars indicate the effect of age at pension spending $1 \mathrm{SD}$ above and $1 \mathrm{SD}$ below the mean, respectively 


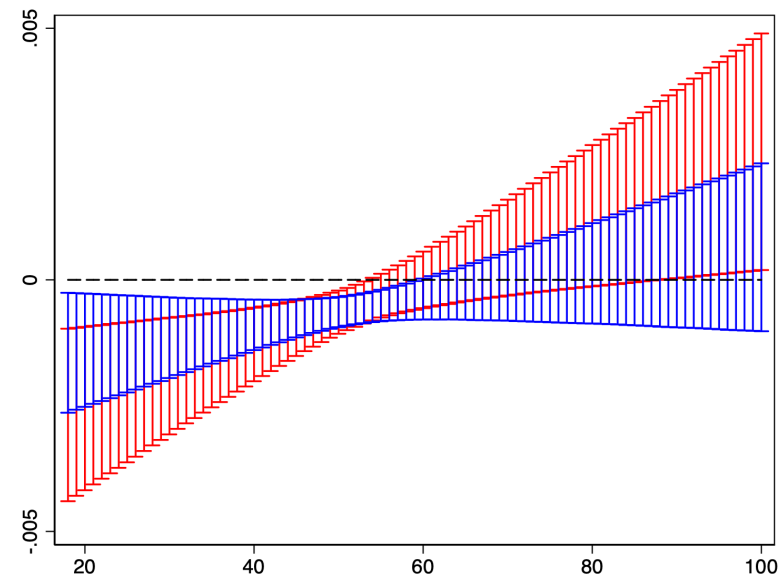

Figure E..6: Marginal Effect of Age at Different Levels of Social Spending (\% of GDP) The effects were generated via simulation utilizing 1000 draws of the variance and co-variance matrices. The red and blue bars indicate the effect of age at social spending 1 $\mathrm{SD}$ above and $1 \mathrm{SD}$ below the mean, respectively.

\begin{tabular}{l|l} 
Western Europe & Former Communist \\
\hline Austria & Albania \\
Belgium & Bulgaria \\
Denmark & Croatia \\
Finland & Czech Republic \\
France & Estonia \\
Germany & Hungary \\
Iceland & Latvia \\
Ireland & Lithuania \\
Italy & Montenegro \\
Luxembourg & Poland \\
Malta & Republic of North Macedonia \\
The Netherlands & Romania \\
Portugal & Slovakia \\
Spain & Slovenia \\
Sweden & \\
United Kingdom &
\end{tabular}

Table E..2: Classification of Countries 